ECONOMIC GROWTH CENTER

YALE UNIVERSITY

P.O. Box 208269

New Haven, CT 06520-8269

http://www.econ.yale.edu/ egcenter/

CENTER DISCUSSION PAPER NO. 877

\title{
DO FAMILY CAPS REDUCE OUT-OF-WEDLOCK BIRTHS? EVIDENCE FROM ARKANSAS, GEORGIA INDIANA, NEW JERSEY AND VIRGINIA
}

\author{
Wendy Tanisha Dyer \\ University of California, San Francisco \\ and \\ Robert W. Fairlie \\ Yale University \& \\ University of California, Santa Cruz
}

December 2003

Notes: Center Discussion Papers are preliminary materials circulated to stimulate discussions and critical comments.

We would like to thank Rebecca London, Marianne Page and Ted Joyce for their comments and suggestions. We would also like to thank Hanming Fang for providing data on maximum AFDC benefit levels. Wendy T. Dyer: Center for the Health Professions, University of California, San Francisco, CA 94118, wtdyer@itsa.ucsf.edu; Robert W. Fairlie: Department of Economics, University of California, Santa Cruz, CA 95604, rfairlie@ucsc.edu, http://econ.ucsc.edu/ fairlie.

This paper can be downloaded without charge from the Social Science Research Network electronic library at: http://ssrn.com/abstract=487488

An index to papers in the Economic Growth Center Discussion Paper Series is located at: http://www.econ.yale.edu/ egcenter/research.htm 


\title{
Do Family Caps Reduce Out-of-Wedlock Births? Evidence from Arkansas, Georgia, Indiana, New Jersey and Virginia
}

\begin{abstract}
Using Current Population Survey (CPS) data from 1989 to 1999, we examine the impact of family cap policies, which deny incremental welfare benefits, on out-of-wedlock birth rates. We use the first five states that were granted waivers from the Department of Health and Human Services to implement family caps as "natural experiments." Specifically, we compare trends in out-ofwedlock birth rates in Arkansas, Georgia, Indiana, New Jersey and Virginia to trends in states that did not implement family caps or any other waivers prior to the Personal Responsibility and Work Opportunity Reconciliation Act (PRWORA). We employ several techniques to increase the credibility of results from our "natural experiment," such as the inclusion of multiple comparison groups, controls for differential time trends, and “difference-in-difference-indifferences” estimators. Our regression estimates generally do not provide evidence that family cap policies reduce the incidence of out-of-wedlock births among single, less-educated women with children.
\end{abstract}

Keywords: Welfare, Family Caps, Fertility

JEL Classification: I3, J1 


\section{Introduction}

On September 13, 1999, the U.S. Department of Health and Human Services awarded Alabama, California, the District of Columbia, Massachusetts, and Michigan each \$20 million for achieving the largest decreases in out-of-wedlock births between 1994-95 and 1996-97. These were the first awards, which will be made annually, granted as part of the 1996 Personal Responsibility and Work Opportunity Reconciliation Act (PRWORA) to encourage states to reduce non-marital childbearing. One of the most controversial policies that many states have used to combat out-of-wedlock births is the family cap or child exclusion policy, which eliminates the extra monetary benefits traditionally entitled to women who have additional children while receiving welfare. ${ }^{1}$ Seventeen states implemented family caps as waivers to the federal requirements of the original Aid to Families with Dependent Children (AFDC) program, and several additional states have implemented family caps since PRWORA was enacted (Crouse, 1999).

Supporters of the family cap policy argue that incremental benefits encourage welfare recipients to have additional out-of-wedlock children, and, thus, the elimination of these benefits will reduce this "perverse" incentive (DHHS, 1997). This argument is supported by the standard economic model of fertility, which posits that the demand for children decreases when the net cost of having children increases. ${ }^{2}$ Because the removal of incremental benefits increases the net cost of having children, it is suggested that family cap policies will reduce fertility. This theory, however, does not offer a prediction regarding the size of the effect on fertility. For example, the effects may be small if many pregnancies are unplanned, incremental benefit levels are low relative to the perceived costs of raising children, nonpecuniary factors dominant the fertility decision, or expected welfare durations are short.

\footnotetext{
${ }^{1}$ Prior to 1992, all states provided incremental increases to welfare benefits for additional children. These monthly incremental benefits ranged from \$24 to \$134 in 1990.

${ }^{2}$ See Becker (1981).
} 
Interestingly, the experimental evaluations accompanying family cap waivers in New Jersey and Arkansas do not provide strong evidence of a negative effect on fertility (Camasso, et al. 1998 and Turtora, Benda and Turney 1997). However, these family cap evaluations have been criticized extensively (see Maynard, et al. 1998 for example). In both the New Jersey and Arkansas experiments it was found that many of the AFDC recipients in the control group thought they were subject to the family cap. The New Jersey experiment also was criticized because it was found that some of the AFDC recipients in the experimental group did not report births to welfare officials because these births did not result in increased benefits. Nonexperimental studies of the impact of family cap policies have largely provided mixed results. Most of these studies, however, rely on state-level data or provide only indirect evidence on the effects of family caps.

In this paper, we contribute to the literature by providing evidence from the first five states that were granted waivers from the Department of Health and Human Services to implement family caps. Using microdata from the 1989 to 1999 Current Population Survey (CPS) Outgoing Rotation Group (ORG) files, we compare trends in out-of-wedlock birth rates among single, less-educated women with children in Arkansas, Georgia, Indiana, New Jersey and Virginia to several sets of comparison states that did not implement family caps or any other waivers during our sample period, which was prior to the implementation of Temporary Assistance for Needy Families (TANF) programs. ${ }^{3}$ We also compare trends in birth rates between groups of women who are differentially affected by family cap policies (single vs. married) and interact these two trends to create a "difference-in-difference-in-differences" estimate of the effect. The results from our analysis of birth rates are based on the experiences of several states and should be less susceptible to "contamination bias" and underreporting of births than the experimental evaluation results. Our econometric modeling of the birth decision at the 
micro level, exclusion of post-TANF years, and use of less-educated married women as an additional control group differs from most of the non-experimental literature on family caps.

\section{Past Literature}

Several recent studies have examined the impacts of family caps on fertility. We first briefly examine the evidence from the experimental evaluations that accompanied family cap waivers in New Jersey and Arkansas. ${ }^{4}$ In the evaluation of New Jersey's Family Development Program, Camasso, et al. (1998) find that birth rates among the experimental group of AFDC recipients who were subject to the cap fell from 11 percent in 1992-93 to six percent in 1994-95. ${ }^{5}$ They also find, however, that the decline in birth rates among the control group of AFDC recipients who were not subject to the cap was nearly identical, suggesting that the family cap had little impact. The results from the evaluation of the Arkansas family cap waiver similarly indicate no statistical difference between trends in birth rates among the experimental and control groups of AFDC recipients.

Notably, these family cap evaluations have been criticized for two main reasons. First, in both the New Jersey and Arkansas experiments it was found that many of the AFDC recipients in the control group thought they were subject to the family cap. ${ }^{6}$ This "contamination bias" may have allowed the family cap to affect the behavior of the control group making it difficult to identify policy effects from a comparison of trends in birth rates between the two groups. Second, the New Jersey experiment also was criticized because it was found that some of the

\footnotetext{
${ }^{3}$ We do not include post-TANF years in the analysis period because of the substantial differences in welfare programs across states resulting from the implementation of TANF programs, making it difficult to isolate the effects of family caps.

${ }^{4}$ See Grogger, Karoly and Klerman (2002) for a more detailed review of the experimental evidence.

${ }^{5}$ New Jersey's family cap policy was implemented as part of the state's Family Development Program.

${ }^{6}$ In the evaluation of the Arkansas experiment, Turturro, Benda, and Turney (1997) note that some AFDC caseworkers "reported that they simply told clients that a family cap on benefits may apply to them" (p. 2). Maynard, et al. (1998) cite an article in the Wall Street Journal that reports survey results indicating that in the New Jersey experiment the control group was as likely to believe that the family cap applied to them as the experimental group.
} 
AFDC recipients in the experimental group did not report births to welfare officials because these births did not result in increased benefits (see Maynard, et al. 1998 for more details). Thus, the reported birth rates of the AFDC recipients subject to the family cap in New Jersey likely were understated.

In response to these concerns over the experimental design and the publicity generated by the controversial family cap policy, the New Jersey research team developed a quasiexperimental design to compare actual outcomes under the Family Development Program to projected outcomes in the absence of the program (Camasso, et al. 1998). Using administrative welfare data and Medicaid claims files from the New Jersey Department of Human Services, they find evidence of a significant decline in births to AFDC recipients after implementation of the program.

Other non-experimental studies of the impact of family cap policies provide mixed results. Horvath-Rose and Peters (2001) use state-level data from 1984 to 1996 to measure the impact of welfare waivers, including family caps, on the ratio of non-marital to marital births. Estimating fixed-effect regression models, they find that family cap policies have a negative and statistically significant effect on the non-marital birth ratio. Using Vital Statistics Natality Data from 1989 to 1998 compiled by the U.S. National Center for Health Statistics, Kearney (2003) explores whether family cap policies reduce the number of births in states implementing them. The results from her fixed effects regressions using state-level data for log births do not provide evidence that family caps reduce births or additional births to women ages 15-34. Mach (2001) uses matched data from the March CPS to examine the effects of family caps on fertility. She finds that the fertility of welfare recipients, but not all women, is roughly 10 percent lower when subject to family caps. Welfare receipt, however, may be endogenous and the use of all other women as a control group for studying the effects of family caps on welfare recipients may be problematic because the groups differ substantially in levels of education, marriage rates and employment rates. 
Joyce, et al. (2003) use state-level data aggregated from induced termination of pregnancy files, national nativity files, and the CPS to explore the relationship between family caps, and birth and abortions. They use birth and abortion rate data for 24 states over the period from 1992 to 1999 and employ a difference-in-difference-in-differences estimator which identifies the effects of family caps from a comparison of changes over time in birth and abortion rates between women at risk of being affected by family caps and women not at risk of being affected by family caps. They find that trends over the family cap period in birth and abortion rates were similar for women with previous live births (the at-risk group) and women with no previous live births (the not at-risk group), and conclude that the downward trend in birth rates and upward trend in abortion rates are not a response to family caps.

Several additional empirical studies provide indirect evidence on the likely impact of family cap policies by examining the effect of incremental AFDC benefit levels on higher-order births. ${ }^{7}$ These studies use the existing variation in incremental benefit levels across states, time, or both to estimate the size of the effect. ${ }^{8}$ Powers (1994), Argys and Rees (1996), and Robins and Fronstin (1996) find some evidence that incremental benefits have a positive effect on out-ofwedlock birth rates. These findings suggest that family cap policies, which reduce or eliminate incremental benefits, may be effective in discouraging childbearing among welfare recipients. However, Acs (1996), Fairlie and London (1997), and Grogger and Bronars (1996) do not find evidence of a positive effect of incremental benefits on fertility, thus raising doubts about the efficacy of family cap policies.

The empirical evidence on the effects of family cap policies clearly is mixed. We provide new evidence on the effectiveness of these policies by analyzing the birth decisions of

\footnotetext{
${ }^{7}$ See Moffitt $(1992,1998)$ for reviews of the literature on the effect of welfare benefits on any births. Although these studies provide mixed results, Moffit notes that a majority of the more recent studies indicate that welfare benefits have a positive and statistically significant effect on fertility.

${ }^{8}$ In addition to these national level studies, a few state level studies exist. Keefe (1983) finds that the large increase in total and incremental AFDC benefits from 1970 to 1971 in California did not increase fertility
} 
women found in the 1989 to 1999 Current Population Survey (CPS) Outgoing Rotation Group (ORG) files. Specifically, we compare trends in out-of-wedlock birth rates among single, lesseducated women with children in Arkansas, Georgia, Indiana, New Jersey and Virginia to several sets of comparison states that did not implement family caps or any other waivers during our sample period. Our analysis of birth rates differs from the experimental evaluations because it is based on the experiences of several states and should be less susceptible to "contamination bias" and underreporting of births. Specifically, we do not distinguish between women in the experimental and control groups. Instead all women living in a family cap state are considered to be subject to the family cap, and thus we are less concerned that welfare recipients in the control group thought they were subject to the family cap. The CPS is also a household survey and provides no differential incentive to report or not report births between the control and experimental groups. Respondents simply report the number and ages of all children currently living in the household.

Our analysis also differs from recent non-experimental studies of the effects of family caps in that we empirically model the birth decision at the micro level allowing us to include a rich set of controls for individual characteristics and precisely define the samples used for treatment and control groups. To be sure, Mach (2001) also uses microdata from the CPS to estimate regressions for the probability of a birth, but the use of the March CPS (which is one third the size of the ORGs) and matching from one year to the next (which only is possible for less than 50 percent of respondents) results in substantially smaller sample sizes than the ORGs. ${ }^{9}$ The approach we use also differs from Horvath-Rose and Peters (1999) in its focus on out-ofwedlock birth rates instead of the non-marital birth ratio and differs from Kearney (2003), Joyce, et al. (2003) and Mach (2001) in that we exclude post-TANF years because of concerns over the

among recipients in the state. Rank (1989) finds that AFDC recipients in Wisconsin have lower birth rates than women in the general population. 
substantial differences in welfare programs across states resulting from the implementation of TANF. We also provide separate estimates for family cap states allowing for heterogeneity in treatment effects, use multiple sets of control group states, and use less-educated married women with children and their interaction with family cap states (i.e. difference-in-difference-indifferences) as additional control groups. ${ }^{10}$

\section{Empirical Strategy}

\section{AFDC FAMILY CAP WAIVERS}

Prior to the passage of PRWORA in 1996, the Department of Health and Human Services was authorized to waive certain requirements of the federal AFDC program to give states the flexibility to experiment with policies and projects to further the goals of the AFDC program (DHHS, 1997). These AFDC waivers represented the beginning of welfare reform in the 1990's in that they were a response to the widely held belief that AFDC created work disincentives, encouraged out-of-wedlock childbearing and discouraged marriage (DHHS 1997 and Maynard et al, 1998). The majority of AFDC waiver policies can be categorized as follows: family caps, termination/reduction time limits, changes to JOBS work exemptions, changes to JOBS sanctions, increases in earnings disregards, and work requirement time limits (Crouse, 1999). ${ }^{11}$ Out of the six major categories of waivers, family caps were the only policies designed to directly target childbearing incentives, and thus represent the waiver policy most likely to have an impact on fertility.

\footnotetext{
${ }^{9}$ The sample of welfare recipients from the 22 states implementing family caps over the period from 1989 to 2000 includes 568 observations of which 25 experienced births in the March CPS.

${ }^{10}$ Joyce, et al. (2003) also use a difference-in-difference-in-differences estimator, but compare changes in birth rates for less-educated single mothers to birth rates for less-educated single women without children. Identification relies on the assumptions that the birth rate differential between mothers and non-mothers is only affected by the family cap and that non-mothers who desire more than 1 child are not affected by the family cap.

${ }^{11}$ See DHHS (1997) for a complete description of each type of waiver.
} 
The first state to implement a family cap policy was New Jersey in 1992. In the years that followed, several other states implemented family cap policies either as waivers under the AFDC program or as part of their TANF plan. Table 1 lists all states that implemented a family cap policy as of 1998 .

We made the following decisions in determining which of these states to include in our treatment group of family cap states. First, we addressed the issue of whether to include TANF years in our analysis. TANF, which replaced AFDC in 1996, provided states with a substantial amount of flexibility in designing new welfare programs. Given that TANF resulted in major changes to state welfare programs, isolating the effect of the family cap on fertility becomes increasingly difficult in post-TANF years. Therefore, we decided to exclude post-TANF years from our analysis and focus on the effect of family cap policies implemented as waivers under the former AFDC program.

Second, we wanted the post period (i.e. the time period following the implementation of a family cap AFCD waiver) to be of sufficient length for examining policy effects on birth rates. We examined each state's family cap implementation date and grace period and determined that a good cutoff would be summer 1995, which guaranteed more than a year for the post period. The first five states to implement family cap policies as AFDC waivers-Arkansas, Georgia, Indiana, New Jersey, and Virginia - did so by this cutoff date. These states became our treatment group. Other family cap states did not implement their policies until just prior to TANF, which does not allow a sufficient time period for examining policy effects on birth rates in these states.

Among the five family cap states included in our analysis, the loss of monthly incremental benefits ranged from $\$ 42$ in Arkansas to $\$ 102$ in New Jersey. ${ }^{12}$ The specific details of family cap policies varied somewhat across these states. New Jersey, for example, allows

\footnotetext{
${ }^{12}$ The incremental benefit is calculated as the difference between the AFDC maximum benefit for a family of two and the maximum benefit for a family of three. These estimates are from the Urban Institute's Assessing the New Federalism State Database at www.urbaninstitute.org and United States Congress, House Committee on Ways and Means (1992).
} 
capped families to increase their earnings from work without experiencing a decrease in their current cash assistance amount (Gallagher et al, 1998). Similarly, Virginia allows families to retain all child support payments for a child subject to its family cap, while Indiana provides vouchers for goods worth up to half of the incremental benefit increase denied (DHHS, 1997). It also is important to note that most states have a 10-month grace period during which new welfare recipients can give birth to additional children who will not be subject to the family cap (Gallagher et al, 1998). One state, Georgia, had a 24-month grace period under its family cap waiver.

To be sure, four of the five states used in the following "natural experiment" - Georgia, Indiana, New Jersey and Virginia - also implemented other waivers under AFDC. Indiana and Virginia implemented a termination or reduction time limit waiver. Indiana, New Jersey and Virginia implemented changes to JOBS work exemptions, and Georgia, Indiana, New Jersey and Virginia had waivers for JOBS sanctions. Virginia also implemented a work requirement time limit and an increased earnings disregard waiver. Finally, Indiana implemented a waiver of the 100-hour rule of its AFDC-UP program (DHHS 1997 and Crouse 1999).

Although these waivers may alter the opportunity costs of having children, they do not directly target the fertility decisions of welfare recipients, and thus are less likely to have an effect on out-of-wedlock births than the family cap. In support of this assertion, Horvath-Rose and Peters (1999) find that the only waivers that had a consistently negative effect on the ratio of nonmarital to marital births are the family cap and AFDC-UP waivers (although only for teenagers). Furthermore, the waivers, with the possible exception of the increased earnings disregard waiver in Virginia, were generally intended to reduce AFDC caseloads, and thus should have a negative effect, if any, on non-marital fertility. ${ }^{13}$ It is useful to note, however, that a major difficulty in this

\footnotetext{
${ }^{13}$ Horvath-Rose and Peters (1999) note that the effect of the increased earnings disregard on non-marital fertility is ambiguous because it both increases eligibility for welfare and increases the opportunity cost of
} 
area of research is identifying the independent effects of specific waivers or TANF policies. We return to this issue when we draw conclusions about our results.

\section{COMPARISON GROUP OF NON-FAMILY CAP STATES}

To examine whether the family cap policies implemented in Arkansas, Georgia, Indiana, New Jersey, and Virginia had an effect on fertility, we compare trends in out-of-wedlock birth rates between these five "family cap" states and states that did not implement a family cap or any other waiver during our sample period. For brevity, we refer to these five states as "family cap" states in the analysis although four of them implemented additional waivers. A simple approach is to compare mean outcomes between the treatment group (i.e. family cap states) and comparison group (i.e. non-family cap states) in the time period before the policy change (the pre period) and in the time period after the policy change (the post period). ${ }^{14}$ Assuming that the implementation of family cap policies is the only factor differentially affecting fertility between the treatment and comparison groups, a negative "difference-in-differences" estimate implies that family cap policies reduced out-of-wedlock birth rates.

To create our comparison group of non-family cap states, we considered several things. First, we wanted to remove the potential effects of any waivers on post-period observations. To accomplish this, we identified when each non-family cap state implemented its first AFDC waiver. Then we excluded observations that fell in the time period following implementation of any AFDC waiver. Second, as with the treatment group of family cap states, we wanted the post period for each comparison state to be of sufficient length for our analysis. We chose November

having an additional child on welfare. See Horvath-Rose and Peters (1999) for a thorough discussion of the expected effects of all AFDC waivers on non-marital childbearing.

${ }^{14}$ In defining the pre and post periods, we take into account each family cap state's grace period. Georgia, for example, had a 24-month grace period. Therefore, the earliest date its family cap (implemented in January 1994) would have applied to a newborn is January 1996. Since our focus is on the decision to have an out-of-wedlock birth, the earliest an AFDC recipient in Georgia could have decided to have an additional child that would be subject to the family cap is May 1995. Thus, Georgia's post period begins on May 1995. 
1995 as the cutoff as this guaranteed that each state in the comparison group contributed at least one full year of post period observations. Therefore, we excluded all states that implemented any AFDC waiver before November 1995. Finally, we excluded all observations in post-TANF years. In the end, the observations from our comparison group of states should be free of both waiver and TANF effects.

As a result of these decisions in creating our treatment and comparison groups of states, the post period for each family cap state ends in the month prior to when the state implemented its TANF program. The post period end date for each non-family cap state in our comparison group is the minimum of either the TANF implementation date or the implementation date of any AFDC waiver. The post-period end date, therefore, varies by state.

After applying the aforementioned criteria, the full comparison group consists of 28 nonfamily cap states, located throughout the United States. These states are listed in Table 2. In comparing out-of-wedlock birth rates between our family cap and non-family cap states, we also utilize more geographically restricted comparison groups that consist of subsets of states from our full comparison group. These subsets are non-family cap states in the South and those in the Northeast.

Before proceeding with the analysis of trends in out-of-wedlock birth rates, it is useful to compare trends in a few alternative factors that may have differentially affected fertility between family cap and non-family cap states. In Table 2, we report AFDC maximum benefit levels, abortion providers, and unemployment rates for the years 1992 and 1996 for each state in our analysis. These years roughly correspond to the periods before and after the implementation of family cap policies in our five states. Large differences in the trends in these variables across states could contribute to differential trends in out-of-wedlock birth rates between family cap states and non-family cap states.

Interestingly, the trends in AFDC benefit levels were very similar across the included states. In fact, all five family cap states and 11 non-family cap states had essentially the same 
decline in maximum benefit levels for a family of three. ${ }^{15}$ Almost all other comparison states experienced declines in AFDC benefit levels from 1992 to 1996 of a similar magnitude.

Oklahoma experienced a decline of 20 percent, while Kentucky and New Mexico experienced an increase in AFDC benefit levels from 1992 to 1996. Other than these exceptions, the trends in AFDC benefit levels did not differ substantially between the family cap and non-family cap states. For a more formal test, we also regressed AFDC benefit levels on state fixed effects, a dummy for 1996, and an interaction between family cap states and 1996. The coefficient estimate on the family cap state and 1996 interaction is small and statistically insignificant.

Most states experienced large decreases in the number of abortion providers from 1992 to 1996. ${ }^{16}$ More importantly for this analysis, however, is that the declines in the number of abortion providers among family cap states were comparable to the declines in most non-family cap states. The main exception was New Jersey, which experienced an increase of six abortion providers from 1992 to 1996. This may have an effect on trends in out-of-wedlock births in New Jersey or be the result of these trends. Finally, changes in economic conditions (as measured by unemployment rates) from 1992 to 1996 in the family cap states did not differ substantially from those in non-family cap states. Unemployment rates generally declined substantially between these two years. $^{17}$

Overall, trends in AFDC benefit levels, abortion providers, and unemployment rates were fairly comparable between family cap and non-family cap states. This is important because glaring differences in these trends could signal that our choice of a comparison group is inappropriate.

\footnotetext{
${ }^{15}$ The 11 percent decline in these states was due to constant nominal benefit levels between 1992 and 1996 and an increase in the CPI of 11 percent.

${ }^{16}$ Unfortunately, we do not have statistics on the size of providers.

${ }^{17}$ We also find small and statistically insignificant coefficients on a family cap state - 1996 interaction in regressions for abortion providers and unemployment rates.
} 


\section{ECONOMETRIC MODEL}

In Section 4, we first compare trends in out-of-wedlock birth rates in Arkansas, Georgia, Indiana, New Jersey and Virginia to trends in states that did not implement family caps or any other waivers prior to PRWORA. Although a comparison of these trends may be informative, it will not control for the potential effects of differential trends in demographic characteristics. To control for these factors, we estimate equations for the probability of a birth using our sample of single, less-educated women with children. Formally, we assume that fertility is determined by an unobserved latent variable

$$
B_{i s t}^{*}=\mu_{s}+\gamma_{t}+\phi^{\prime} P_{s t}+\delta^{\prime} F_{s}^{*} P_{s t}+\beta^{\prime} X_{i s t}+\varepsilon_{i s t},
$$

where $F_{s}$ is a dummy variable indicating a family cap state, $P_{s t}$ is a dummy variable indicating a post-family cap time period observation, $X_{i s t}$ is a vector of individual characteristics, $\mu_{s}$ is a fixed effect for state $s, \gamma_{t}$ is a fixed effect for year $t$, and $\varepsilon_{i s t}$ is the disturbance term. ${ }^{18}$ Only the dichotomous variable, $B_{i s t}$, is observed, however. It equals 1 if $B_{\text {ist }}{ }^{*} \geq 0$ (denoting that a birth occurred in the previous year) and equals 0 otherwise (denoting no birth). If we take $\varepsilon_{\text {ist }}$ to be normally distributed, the assumptions imply that the data are described by a probit model. Although the normality assumption should only be taken as an approximation, the probit model provides a useful descriptive model for the binary event that a birth occurred. We also adjust the standard errors for the presence of common random shocks at the state level to address concerns regarding understated standard errors and serially correlated outcomes for the U.S. grouped regressions (see Betrand, Duflo and Mullainathan 2002). For the other specifications, where we do not have a large enough number of groups, we estimate heteroscedasticity-robust (i.e. HuberWhite) standard errors.

\footnotetext{
${ }^{18}$ Note that the "main" effect for family cap states, $F_{s}$, is captured by the state fixed effects, but that the "main" effect for the post period, $P_{s t}$, is not captured by the year fixed effects because it is determined by the month of implementation.
} 
In Equation (2.1), the effectiveness of the family cap policy is determined by examining the sign and statistical significance of $\delta^{19}$ A negative and statistically significant estimate of $\delta$ provides evidence that family cap policies reduce the birth rate among single, less educated women with children. We can also examine the robustness of this estimate by selecting several different treatment and comparison states.

A potential concern with this interpretation of $\delta$ is that there may have existed differential trends in out-of-wedlock birth rates between the family cap and comparison states that began before the implementation of family cap policies. For example, a negative estimate of $\delta$ may simply be due to a more rapid downward trend over the past decade in the out-of-wedlock birth rate in the family cap states than in the non-family cap states. To control for this potential bias, we also estimate probit regressions that include a separate linear time trend, $t$, for the family cap states

$$
B_{i s t}^{*}=\mu_{s}+\gamma_{t}+\phi^{\prime} P_{s t}+\lambda^{\prime} t_{t}^{*} F_{s}+\delta^{\prime} F_{s}^{*} P_{s t}+\beta^{\prime} X_{i s t}+\varepsilon_{i s t}
$$

Another approach to examining the effectiveness of the family cap policy is to compare trends in birth rates between single, less-educated women with children and married, lesseducated women with children within family cap states. These married women theoretically should not be affected (or at least only minimally affected) by family cap policies because they are not typically eligible to receive AFDC benefits, but may be affected similarly by other factors affecting fertility among low-income women. ${ }^{20}$ Therefore, we use married, less-educated women with children as a comparison group and restrict our sample to only family cap states. The equation is

$$
B_{i s t}{ }^{*}=\mu_{s}+\gamma_{t}+\phi_{1}{ }^{\prime} P_{s t}+\phi_{2}{ }^{\prime} S_{i s t}+\delta^{\prime} S_{i s t} * P_{s t}+\beta^{\prime} X_{i s t}+\varepsilon_{i s t}
$$

\footnotetext{
${ }^{19}$ We are implicitly assuming that the effects of family caps are immediate and do not evolve over time. Although there may exist spillover effects or incomplete information regarding the policies implying larger effects over time, our approach represents an approximation to this dynamic process.

${ }^{20}$ Married women are eligible for welfare benefits through the AFDC-UP program. However, only seven percent of all families on AFDC receive benefits through the AFDC-UP program (United States Congress, House Committee on Ways and Means, 1992).
} 
where $S_{i s t}$ is a dummy variable indicating that the woman is single. Again, in this equation a negative and statistically significant estimate of $\delta$ provides evidence that family caps reduce outof-wedlock births.

A combination of the identification strategies used in Equations (2.1) and (2.3) suggests that the family cap should only (or at least largely) affect the fertility decisions of single women with children who live in family cap states during the post-family cap period. Therefore, an additional estimation strategy is the "difference-in-difference-in-differences" estimator (2.4) $B_{i s t}{ }^{*}=\mu_{s}+\gamma_{t}+\phi_{1}{ }^{\prime} P_{s t}+\phi_{2}{ }^{\prime} S_{i s t}+\alpha_{1}{ }^{\prime} S_{i s t} * F_{s}+\alpha_{2}{ }^{\prime} S_{i s t} * P_{s t}+\alpha_{3}{ }^{\prime} F_{s} * P_{s t}+\delta^{\prime} S_{i s t} * F_{s} * P_{s t}+\beta^{\prime} X_{i s t}+\varepsilon_{i s t}$. In this specification, identification of $\delta$ comes from comparing the change over time in the difference between the birth rates of single and married women in family cap states to the change over time in the difference between the birth rates in non-family cap states. The use of this and the previous alternative approaches of specifying the natural experiment provide additional evidence for testing the hypothesis.

\section{Data}

We use data from the 1989 to 1999 Current Population Survey (CPS) Outgoing Rotation Group (ORG) files. The ORG files contain annual samples that are roughly three times larger than those from a monthly CPS, such as the commonly used March Annual Demographic Files. The large sample sizes are important for identifying the potential effects of family caps. Also, the CPS microdata provide detailed demographic information on the mother to include as controls in the regressions and allow us to estimate models for the probability of birth because they include observations for women not giving birth in the previous year.

We create our sample by first matching mothers to their children. The CPS assigns each household an identification number (which is made unique within each year by affixing the month and state variables to this number), and each individual within a household is assigned a 
unique identifier number. These variables are used in conjunction with spouse and parent identifiers and the edited relationship to household head variable to match mothers to their children. Because the CPS collects individual information by household, it is possible to match a child to his/her mother only if that child is living in the same household as his/her mother. Thus, we measure the number of children ages 18 and under who live in the household and not the number of previous births.

After matching children to their mothers for the years 1989-1999, we confine our primary sample to those women who are most likely to meet AFDC eligibility requirements. Therefore, we restrict our sample to single, less educated (i.e. high school graduate or less) females who have at least one previous child and who are between the ages of 15 and 45 . In some of the following analyses, however, we also include less-educated, married women with children as a comparison group. The education-level restriction is imposed because the majority of welfare participants whose educational status is known have no more than a high school education (United States Congress, House Committee on Ways and Means, 1998).

To identify whether a woman has a birth in the survey year, we examine the age of her matched children. If a woman has a child who is less than one year old, then we assume that that woman gave birth in the preceding year. ${ }^{21}$ Because family cap policies aim to influence a woman's decision to have an additional out-of-wedlock child, we take the year and month of each observation and lag it 15 months. The purpose of the time lag is to take into account the ninemonth interval between the decision to have a child (or at least the decision to use contraceptives) and the actual birth of the child. We also add 6 months to this lag because it represents the midpoint over the previous year when the birth may have occurred.

\footnotetext{
${ }^{21}$ Note, for example, that twins or two children born separately in the same 12-month period are not double counted.
} 


\section{Results}

\section{TRENDS IN OUT-OF-WEDLOCK BIRTH RATES}

Figure 1 displays birth rates for single, less educated mothers (ages 15-45) in family cap and non-family cap states for 1989 to 1998 . Birth rates among our sample of women show a downward trend over the ten-year time span from 1989 to 1998 . This is true for both family cap and non-family cap states. From 1989 to 1991, birth rates increased in both family cap and nonfamily cap states. In family cap states, the birth rate climbed from $6.2 \%$ in 1989 to $8.6 \%$ in 1991 . In non-family cap states, the birth rate increased from $6.5 \%$ in 1989 to a high of $7.4 \%$ in 1991 . After 1991, the average birth rate of our sample of females in family cap states fell by over 2 percentage points to $6.5 \%$ in 1992 , and then bounced to its peak of $9 \%$ in 1993 before declining sharply to a low of $4.8 \%$ in $1994 .^{22}$ From 1994 to 1998 , the birth rate in family cap states continued to fluctuate, though less dramatically, and ended the period lower than it was prior to 1994. The average birth rate in non-family cap states followed a smoother downward path declining from a high of $7.4 \%$ in 1991 to a low of 5.7\% in 1994. After 1994, the birth rate in non-family cap states increased moderately to $6.3 \%$ in 1997 and then falls to $6 \%$ in 1998 .

Overall, birth rates in the family cap states followed a pattern similar to those in nonfamily cap states. The data also indicate that birth rates in family cap states were generally higher than birth rates in non-family cap states from 1989 to 1993, whereas they were lower from 1994 to 1998 , suggesting that family cap policies may have been effective in lowering birth rates among single, less educated mothers.

Table 3 presents pre and post period out-of-wedlock birth rates for the family cap and non-family cap states in our analysis. Comparing totals, we find that the birth rate for family cap

\footnotetext{
${ }^{22}$ A possible explanation for this sharp decrease may be the changes to CPS variables during this same time period. Several variables experienced significant changes or were discontinued after 1993. However, we took considerable care to account for any changes in variables and to ensure consistency in matching mothers to children over the years.
} 
states $(7.3 \%)$ during the pre period was slightly higher than the birth rate for non-family cap states $(6.9 \%)$. In the post period, the birth rate decreased in both the family cap and non-family cap states. The decrease in the birth rate was greater in family cap states (1.7 percentage points) than in non-family cap states (1.0 percentage point), suggesting that family cap policies may have reduced out-of-wedlock birth rates.

Turning our attention to the Northeast, we find that New Jersey experienced a large decrease in its mean birth rate- 2.5 percentage points-while non-family cap states in the Northeast experienced a smaller decrease (1.1 percentage points) from the pre to post period. Focusing on Southern states, however, we find a very different pattern. The birth rate in the Southern family cap states remained essentially the same over the pre to the post period while it decreased by 1.1 percentage points in the Southern non-family cap states. Overall, these results provide evidence both supporting and contradicting the hypothesis that family cap policies reduced out-of-wedlock birth rates. These results, however, are only suggestive. We now need to control for changes in demographic characteristics.

\section{ESTIMATES OF THE EFFECTS OF FAMILY CAP POLICIES ON FERTILITY}

To control for the potential effects of differential trends in demographic characteristics, we estimate probit regressions for the probability of birth using our sample of single, lesseducated women with children. Table 4 reports coefficient estimates, standard errors and marginal effects for Equation (2.1). ${ }^{23}$ The dependent variable equals one if the woman had a birth in the previous year and equals zero otherwise. In addition to state and year fixed effects, a post-period dummy, unemployment rates, and maximum AFDC benefit levels, we include controls for several individual characteristics affecting fertility. The coefficient estimates on these explanatory variables have the expected signs. For example, we find that graduating from 
high school, living with parents, and having more previous children (up to 3 children) decrease the probability of having a child. We also find that younger, non-white and never married women have a higher probability of giving birth, all else equal.

We now turn to the results for the family cap policies. We first discuss estimates for Specification 1, which includes the full sample of family cap and non-family cap states. The coefficient on the family cap state and post period interaction variable is positive and small in magnitude. ${ }^{24}$ The point estimate implies that family cap policies increase the probability of birth by 0.41 percentage points. The coefficient, however, is not statistically significant. Although this estimate does not provide evidence that family cap policies reduce out-of-wedlock birth rates among single, less-educated mothers, we cannot rule out the possibility that negative effects exist. A 95 percent confidence interval for our point estimate would be -0.1175 to 0.1896 . Thus, we cannot with reasonable confidence rule out negative effects that are smaller in absolute value than -1.3 percentage points.

In Specification 1, the family cap effect is identified by grouping all family cap states; however, there may exist some important differences across states. In Specification 2, we interact each of the five family cap states with the post-period dummy variable. This allows for the identification of separate family cap effects for the five states, which may be justified due to differences in incremental AFDC benefit levels and additional AFDC waivers. Although none of the coefficients are statistically significant, we find both positive and negative coefficients. The post-period interactions for Indiana and Virginia are negative, whereas the interactions are positive for Arkansas, Georgia and New Jersey.

\footnotetext{
${ }^{23}$ The marginal effect or average derivative equals $\delta \Sigma \varphi\left(Z_{i t}{ }^{\prime} \pi\right) / N T$, where $\delta$ is the coefficient on the family cap state/post-time period interaction variable, $\phi$ is the normal probability density function, $Z_{i t}$ includes all independent variables, and $N T$ is the total sample size.

${ }^{24}$ We also estimate this equation using a treatment group consisting of all states that implemented AFDC family cap waivers prior to TANF. Thus, the treatment group includes New Jersey, Georgia, Arkansas, Virginia, Indiana, Delaware, Mississippi, Arizona, Massachusetts, Nebraska, Illinois, Connecticut, Wisconsin, Maryland, North Carolina, and California. The estimated effect of the family cap is small, positive and statistically insignificant, similar to that in our original regression with only five family cap states in the treatment group (the coefficient and standard error are 0.006 and 0.0583 , respectively).
} 
To check the robustness of the unexpected positive coefficients for Arkansas, Georgia, and New Jersey, we conduct separate analyses for the South and Northeast. In Specification 3, we only include family cap and non-family cap states in the South. By focusing on the South, we are limiting our comparison group of states to those that are more similar to Arkansas, Georgia and Virginia. We find a positive, although statistically insignificant, coefficient on the family cap state and post-period interaction variable. This is consistent with a weighted average of the positive coefficients found for Arkansas and Georgia and the negative coefficient found for Virginia in the previous specification. In fact, the inclusion of only Southern non-family cap states in the comparison group makes little difference to the coefficient estimates. In Specification 4, we include separate post-period interactions for Arkansas, Georgia and Virginia. We find very similar coefficient estimates on these post-period interactions as those reported in Specification 2, which use all non-family cap states in the United States as the comparison group.

We also conduct a separate analysis for New Jersey. As noted above, New Jersey was the first state to implement a family cap policy, and, thus, received a lot of attention. To create a more appropriate comparison group, we select only non-family cap states in the Northeast. Although the coefficient is now negative, it remains statistically insignificant. ${ }^{25}$ Therefore, estimates using only Northeastern states as a comparison group for New Jersey do not provide evidence suggesting that we change our conclusions regarding the effects of the family cap in this state.

Overall, the results presented in Table 4 do not provide evidence that family cap policies have a negative effect on out-of-wedlock birth rates (although confidence intervals for our point estimates do not allow us to rule out negative effects). All of the estimated coefficients on the family cap state and post-period interactions are statistically insignificant and many of them are

\footnotetext{
${ }^{25}$ We also estimate a probit regression including only Connecticut, New York and Pennsylvania as comparison states. The coefficient estimate on the New Jersey*Post Period interaction variable is -0.0964 and the standard error is 0.1057 .
} 
positive. It is important to note that our results do not vary much from those of the formal experimental evaluations of New Jersey's and Arkansas' family cap waivers. These evaluations do not provide strong evidence of a negative effect on fertility. Interestingly, our analysis, which uses multiple comparison groups and data from a source less susceptible to contamination bias, also does not provide evidence that family caps were effective in reducing out-of-wedlock births.

As noted above, Georgia, Indiana, New Jersey and Virginia implemented additional waivers at the same time as their family cap policies. Therefore, our estimated effects of family cap policies for these states may include the effects of other waivers. We argue, however, that the concurrent implementation of these waivers should not change our conclusions regarding the effects of the family cap policy. First, the family cap was the only AFDC waiver that specifically targeted childbearing incentives. The family cap explicitly denied additional benefits to women having children while receiving AFDC, whereas the other waivers implemented by these states -time limits (Indiana and Virginia), JOBS sanctions (Georgia, Indiana, New Jersey and Virginia), changes to JOBS work exemptions (Indiana, New Jersey and Virginia), work requirement time limit (Virginia), and increased earnings disregards (Virginia) -- generally created incentives to work and/or leave the AFDC rolls. Furthermore, the AFDC-UP waiver in Indiana may have reduced out-of-wedlock birth rates indirectly by increasing the probability of marriage. We discuss the broader issue of how marriage may affect our results below. Although these policies may have indirectly affected the fertility decisions of AFDC recipients, their effects should have been small relative to the effects of family cap policies.

Second, and perhaps more importantly, if the waivers had an effect, their effects generally should be negative, which is the same as the hypothesized effect of the family cap. ${ }^{26}$ Our estimates do not provide evidence that the implementation of family cap policies and the

\footnotetext{
${ }^{26}$ As noted above, the increased earnings disregard may have increased non-marital fertility by expanding eligibility for welfare. The hypothesized positive effect of this policy, especially when combined with the family cap, is unlikely, however, as the opportunity cost of having an additional child on welfare is large.
} 
other aforementioned waivers had a negative effect on the incidence of out-of-wedlock births. Therefore, we conclude that our estimates do not provide evidence that family caps affected fertility. We also should note that the one family cap state that did not implement additional waivers -- Arkansas -- had a positive (although statistically insignificant) coefficient on the post period-family cap interaction variable.

We estimated two additional regressions to further explore these issues. First, we estimated a regression which included all possible control states. This modified control group includes states that also implemented non-family cap welfare waivers in addition to our previous control states. The coefficient on the family cap post variable remains very small and statistically insignificant (the coefficient and standard error are -0.0081 and 0.0749 , respectively).

We also estimated a specification that includes all states and incorporates waiver controls. The experimental group now includes all states implementing a family cap and the control group includes all other states. We include dummy variables for each of the major AFDC waivers (i.e. family caps, termination/reduction time limits, changes to JOBS work exemptions, changes to JOBS sanctions, increases in earnings disregards, and work requirement time limits, Crouse 1999). We continue to exclude post-TANF observations for all states. The results generally support our assertions regarding the other AFDC waivers. The estimated coefficients on the AFDC waiver dummy variables are small and not statistically significant. The only exception is that we find a negative and statistically significant coefficient on the work requirement time limits dummy variable. We should note, however, that work requirement time limits were usually implemented at the same time as the other work-related waivers and our estimates are somewhat sensitive to the inclusion of a couple of outlier states. It is important to also note that in our main specifications reported above the only experimental state that implemented a work requirement time limit is Virginia and none of the control states implemented any waivers. Furthermore, the estimated coefficient on the family cap waiver 
dummy remains small and statistically insignificant (the coefficient and standard error are 0.0117 and 0.0639 , respectively). Therefore, the inclusion of wavier controls and additional states does not change our main conclusion regarding the effects of family caps.

\section{DIFFERENTIAL TIME TRENDS}

A problem arises with the preceding interpretation of the "difference-in-differences" estimates if family cap and non-family cap states had differential underlying trends in out-ofwedlock birth rates during the 1990s. These trends may have "washed out" the observed effects of family cap policies. To address these concerns, we estimate probit regressions that include separate time trends for family cap and non-family cap states. Table 5 reports estimates for Equation (2.2), which includes a linear time trend interacted with family cap states. The main time trend is captured in the year fixed effects. The coefficient estimates on the family cap-time trend interactions in all three specifications are small and statistically insignificant, and thus do not provide evidence that family cap states experienced a different trend in out-of-wedlock birth rates.

In Table 5, Specification 1 includes the full sample of family cap and non-family cap states. The estimated coefficient on the family cap state and post period interaction variable is small, negative and statistically insignificant. Specification 2 focuses on family cap and nonfamily cap states in the South. As before, the coefficient on the family cap state and post period interaction is positive and insignificant. The results for Specification 3, which includes only New Jersey and non-family cap states in the Northeast, are interesting in terms of the magnitude of the estimated effect of New Jersey's family cap policy. The coefficient on the New Jersey and postperiod interaction variable is negative and large in magnitude. Although statistically insignificant, the point estimate implies that New Jersey's family cap policy decreased the probability of out-of-wedlock births among single, less educated mothers by 3.25 percentage points. 
Again, the lack of statistical significance weakens any inferences from these results. Nevertheless, the estimates do not provide any evidence suggesting that family caps reduced fertility.

The findings from Table 5 also provide some suggestive evidence on the question of whether the family cap policies implemented in our sample of states were in response to upward trends in out-of-wedlock birth rates, and thus represent an endogenous policy intervention. As noted above, however, we do not find evidence indicating that family cap and non-family cap states experienced a differential time trend in fertility. To investigate this further, we ran a second set of regressions with time trend interactions excluding observations from the post family cap period for both family cap states and control states. If family caps were implemented in response to trends in fertility then we should find an upward trend in out-of-wedlock birth rates in family cap states relative to the trend in non-family cap states. We find a small, positive, but statistically insignificant coefficient on the family cap state and time trend interactions in the U.S., South, and Northeast specifications. Although we cannot rule out the possibility that family caps were implemented as a reaction to fertility trends among welfare recipients, our estimates do not provide evidence suggesting that this is the case.

\section{ESTIMATES USING MARRIED WOMEN AS A CONTROL GROUP}

In order to further examine the effectiveness of the family cap, we estimate probit regressions for the probability of birth using married, less educated women with children as the comparison group (Equation (2.3)). We restrict our sample to only family cap states in order to compare trends in birth rates between less educated single and married women with children. In theory, married women should not be affected (or at least only minimally affected) by family cap policies because they typically are not eligible to receive AFDC benefits; however, they may be 
affected similarly by other factors affecting fertility among low-income women. ${ }^{27}$ Thus, the coefficient of interest in Equation (2.3) corresponds to the single woman and post period interaction variable.

Table 6 reports estimates for Equation (2.3). As expected, single women have lower birth rates relative to married women, all else equal. The results for family cap policies are as follows. In Specification 1, we include all five family cap states in our sample. We find a negative and statistically significant coefficient on the interaction of single woman and post period. The point estimate implies that family caps decrease the probability of birth by 1.6 percentage points. Restricting our sample to family cap states in the South (Specification 2), we find a positive, although insignificant, coefficient on the single woman and post period interaction. In Specification 3 we focus on New Jersey. The estimated coefficient on the interaction of single woman and post period is negative and large in magnitude. The coefficient, however, is statistically insignificant.

The use of less-educated married women with children as a comparison group provides some evidence that family caps decrease fertility among single mothers. The evidence, however, only comes from one of the reported specifications.

\section{DIFFERENCE-IN-DIFFERENCE-IN-DIFFERENCES ESTIMATES}

Expanding on the difference-in-differences strategy for estimating the effectiveness of family cap policies, we combine Equations (2.1) and (2.3) to compare changes over time in the difference between the birth rates of single and married women in family cap states to changes over time in the difference between the corresponding birth rates in non-family cap states.

\footnotetext{
${ }^{27}$ To further investigate this assumption we estimated two regressions. First, we estimated a probit regression in which we included a linear time trend interacted with a dummy variable for single mothers using the entire period for control states and the pre-period for family cap states. We do not find evidence of different trends in fertility between single and married women with children. We also estimated a regression in which we only included family cap states and similarly found no evidence of differential trends in fertility between single and married mothers before the implementation of family caps.
} 
Family cap policies should primarily affect the fertility decisions of single women with children who live in family cap states during the post-family cap period. As identified in Equation (2.4), we employ a "difference-in-difference-in-differences" estimator to test this hypothesis.

Table 7 reports estimates for Equation (2.4). The results for the family cap policies are embodied in the estimated coefficients for the triple interaction variable of single woman, family cap state, and post period. Specification 1 includes the full sample of married and single women in family cap and non-family cap states. The coefficient on the triple interaction variable is negative; however, it also is small in magnitude and statistically insignificant. In Specification 2, we include only single and married mothers who live in family cap and non-family cap states in the South. The estimated coefficient on the triple interaction variable is large and positive, although statistically insignificant. Estimating Equation (2.4) including only observations from New Jersey and other Northeastern states (Specification 3), we find a negative, but statistically insignificant coefficient on the triple interaction variable.

The results of the "difference-in-difference-in-differences" estimator do not differ qualitatively from the results reported in Table 4. In all specifications, we find statistically insignificant coefficients, and thus do not find evidence that family caps reduced fertility. These results also are consistent with those of Joyce, et al. (2003) who use state-level data aggregated from induced termination of pregnancy files, national nativity files, and the Current Population Survey and do not find consistent evidence suggesting that family caps affect birth and abortion rates. Interestingly, their sample does not include New Jersey and Georgia and uses a different identification strategy for their difference-in-difference-in-differences estimator. They compare changes in birth rates for less-educated single mothers to changes in birth rates for less-educated single women without children. 


\section{FAMILY CAPS AND MARRIAGE}

One concern with these results and those reported above is that family caps, or possibly the waivers implemented with them, may affect the opportunity costs of marriage. This may have an indirect effect on estimates of the impacts of family caps on out-of-wedlock birth rates by changing the sample composition of single woman with children. In particular, a single mother may be more likely to marry the father of her child with the implementation of family caps because the penalty of marriage is now lower.

We investigate this issue further by estimating two regressions. First, we estimate a regression that includes both less-educated, single and married women with children in the sample, but excludes the interactions between single women, and family cap states, the post period and family cap state*post period. Thus, the family cap effect is identified by a comparison of the change in birth rates among single and married mothers in family cap states and the change in the birth rates among single and married mothers in non-family cap states. If family caps influence the likelihood of marriage it will have no effect on the estimates because single and married mothers are grouped together. The coefficient estimate on the modified family cap state/post period interaction is positive (0.0521) and statistically insignificant.

We also directly investigated the hypothesis of whether family caps affect marriage. Specifically, we estimated a regression in which the dependent variable is the probability of marriage using our sample of less-educated, single and married women with children. We included an interaction between family cap states and the post period. We find a very small and statistically insignificant coefficient on this interaction. Therefore, the estimates do not provide evidence that family caps affected the probability of marriage among less-educated women with children.

Perhaps these results are not entirely surprising. Although family caps may lower the opportunity costs of getting married to the father of the child, they are small relative to the total 
AFDC benefit. Thus, the main opportunity cost of marriage will be the potential loss of the chief component of the AFDC benefit that the woman currently is receiving.

\section{Conclusions}

We use microdata from the 1989 to 1999 Current Population Survey (CPS) Outgoing Rotation Group (ORG) files to examine trends in out-of-wedlock birth rates among single, lesseducated women with children prior to the implementation of state TANF programs. In particular, we compare trends in out-of-wedlock birth rates in the first five states to implement family cap policies -- Arkansas, Georgia, Indiana, New Jersey and Virginia -- to trends in several sets of comparison states that did not implement family caps or other waivers during our sample period. In simple comparisons of trends in birth rates, we find that Indiana, New Jersey, and Virginia experienced larger declines in out-of-wedlock birth rates after the implementation of family cap policies than the relevant comparison group of non-family cap states. We also find, however, that Arkansas and Georgia experienced large increases in out-of-wedlock birth rates over the same period in which a group of comparison states from the South experienced a large decline in out-of-wedlock birth rates.

In our first set of probit regressions for the probability of a birth among single, lesseducated women with children, we do not find evidence that family cap polices have a negative effect on fertility. All of the estimated coefficients for the variable embodying the effect of the family cap policy are statistically insignificant and many of them are positive. Furthermore, even after controlling for differential time trends in out-of-wedlock birth rates between family cap and non-family cap states, we continue to find a lack of statistical significance as well as a positive coefficient for the Southern family cap states. We should note, however, that confidence intervals for the point estimates cannot rule out negative effects.

In the next set of probit regressions, we compare trends in birth rates between single and married mothers in family cap states. Thus, we use less-educated, married women with children 
in family cap states instead of less-educated, single mothers in non-family cap states as the comparison group. Although we use a different source of variation to identify the effects of family cap policies, we find somewhat similar results. The important exception is that we find a negative and statistically significant coefficient in the full specification providing some evidence that family caps reduced out-of-wedlock birth rates.

In our final set of probit regressions, we compare changes over time in the difference between the birth rates of single and married women in family cap states to changes over time in the difference between the birth rates of single and married women in non-family cap states. Using this "difference-in-difference-in-differences" estimator, we do not find evidence that family cap polices reduce the incidence of out-of-wedlock births among single, less-educated women with children.

With the exception of Arkansas, our "family cap" states implemented additional waivers that may have affected fertility. We argue, however, that the implementation of these other waiver policies in Georgia, Indiana, New Jersey and Virginia does not change our conclusions regarding the effectiveness of family cap policies in reducing out-of-wedlock births in these states. This is because we do not expect the additional waivers to have a large negative effect on fertility, and, similar to the family cap, these other AFDC waivers aimed to encourage selfsufficiency among welfare recipients (DHHS, 1997). We also do not find evidence of a family cap effect when experimenting with controls for other waivers and using larger samples of experimental and control states. Thus, our general lack of evidence of a negative effect of the family cap and other waivers on fertility implies that our findings do not support the hypothesis that family cap policies reduce the incidence of out-of-wedlock births.

In general, our estimates do not provide evidence that family cap policies reduce out-ofwedlock birth rates among single, less-educated women with children. The effects of family cap policies on fertility may be limited because incremental benefit levels are substantially lower than the estimated costs of raising a child, many welfare spells are short, the importance of non- 
pecuniary factors, the unanticipated nature of some pregnancies, and the partial offsetting of lost benefits from Food Stamp and Medicaid benefits. ${ }^{28}$ If policymakers aim to reduce fertility among welfare recipients, relying on family caps as the policy tool may not produce the desired results. It remains to be seen, however, if the changes implemented under TANF will have larger effects on out-of-wedlock birth rates.

${ }^{28}$ See Haveman and Wolfe (1995), Anderson (1989), Bane and Ellwood (1994), Zelnik and Kantner (1980), and Maynard, et al (1998) for evidence. 


\section{References}

Acs, Gregory (1996), “The Impact of Welfare on Young Mothers' Subsequent Childbearing Decisions," Journal of Human Resources 31, pp. 898-915.

Anderson, Elijah (1989), "Sex Codes and Family Life Among Poor Inner City Youths," Annals of the American Academy of Political and Social Science 501, pp. 59-78.

Argys, Laura M. and Daniel I. Rees (1996), "The Impact of Welfare Generosity on the Fertility Behavior of Recipients," Center for Research on Economic and Social Policy, University of Colorado, Denver Working Paper No. 9601.

Bane, Mary Jo and David T. Ellwood (1994), Welfare Realities: from Rhetoric to Reform (Cambridge: Harvard University Press).

Becker, Gary S. (1981), A Treatise on the Family, Cambridge: Harvard University Press.

Bertrand, Marianne, Esther Duflo, and Sendhil Mullainathan. 2002. "How Much Should We Trust Differences-in-Differences Estimates?" National Bureau of Economic Research Working Paper No. 8841.

Camasso, Michael, Carol Harvey, Radha Jagannathan, and Mark Killingsworth (1998), A Final Report on the Impact of New Jersey's Family Development Program, Rutgers University.

Crouse, Gil (1999), "State Implementation of Major Changes to Welfare Policies, 1992-1998," Report to the Assistant Secretary for Planning and Evaluation in the United States Department of Health and Human Services. http://aspe.os.dhhs.gov/hsp/Waiver-Policies99/policy_CEA.htm

Department of Health and Human Services [DHHS] (1997), "Setting the Baseline: A Report on State Welfare Waivers," Office of the Assistant Secretary for Planning and Evaluation, United States. http://aspe.hhs.gov/hsp/isp/waiver2/title.htm

Duncan, Greg and Saul Hoffman (1990), "Welfare Benefits, Economic Opportunities, and Outof-Wedlock Births Among Black Teenage Girls,” Demography 27, pp. 519-535.

Fairlie, Robert W. and Rebecca A. London (1997), "The Effect of Incremental Benefit Levels on Births to AFDC Recipients," Journal of Policy Analysis and Management, 16(4): 575-597.

Gallagher, L. Jerome, Megan Gallagher, Kevin Perese, Susan Schreiber, and Keith Watson (1998), "One Year After Federal Welfare Reform: A Description of State Temporary Assistance for Needy Families (TANF) Decisions as of October 1997," Washington, D.C.: The Urban Institute.

Grogger, Jeffrey, Lynn A. Karoly, and Jacob Alex Klerman. 2002. Consequences of Welfare Reform: A Research Synthesis. Santa Monica, CA: RAND.

Grogger, Jeffrey and Stephen G. Bronars. 2001. "The Effect of Welfare Payments on the Marriage and Fertility Behavior of Unwed Mothers: Results from a Twins Experiment," Journal of Political Economy, 109(3). 
Horvath-Rose, Ann and H. Elizabeth Peters. 2001. "Welfare Waivers and Non-Marital Childbearing," For Better and For Worse: State Welfare Reform and the Well-Being of LowIncome Families and Children. New York: Russell Sage Foundation.

Joyce, Ted, Robert Kaestner, Sanders Korenman, and Stanley Henshaw. 2003. "Family Cap Provisions and Changes in Births and Abortions," Baruch College Working Paper.

Kearney, Melissa Schettini. 2003. "Is There an Effect of Incremental Welfare Benefits on Fertility Behavior? A Look at the Family Cap." Journal of Human Resources (forthcoming).

Keefe, David E. (1983), "Governor Reagan, Welfare Reform, and AFDC Fertility," Social Service Review 57, pp. 234-253.

Mach, Traci L. 2001. "Measuring the Impact of Family Caps on Childbearing Decisions," University at Albany Working Paper.

Maynard, Rebecca, Elisabeth Boehnen, Tom Corbett, Gary Sandefur, and Jane Mosley (1998), "Changing Family Formation Behavior Through Welfare Reform," Welfare, the Family, and Reproductive Behavior: Research Perspectives, Ed. Robert A. Moffitt, Washington, D.C.: National Academy Press.

Moffitt, Robert (1992), "Incentive Effects of the U.S. Welfare System: A Review," Journal of Economic Literature 30, pp. 1-61.

Moffitt, Robert A. (1998), “The Effect of Welfare on Marriage and Fertility," Welfare, the Family, and Reproductive Behavior: Research Perspectives, Ed. Robert A. Moffitt, Washington, D.C.: National Academy Press.

Powers, Elizabeth T. (1994), "The Impact of AFDC on Birth Decisions and Program Participation," Federal Reserve Bank of Cleveland Working Paper No. 9408.

Robins, Philip K. and Paul Fronstin (1996), "Welfare Benefits and Birth Decisions of NeverMarried Women," Population Research and Policy Review 15, pp. 21-43.

Turturro, Carolyn, Brent Benda, Howard Turney, James Chastain, Christy Pollack, Lynne Osborn and John Knott (1997), Arkansas Welfare Waiver Demonstration Project: Final Report, July, 1994 through June, 1997, The University of Arkansas at Little Rock School of Social Work.

United States Congress, House Committee on Ways and Means (1992), The 1992 Green Book Overview of Entitlement Programs, Washington, D.C.: U.S. Government Printing Office.

United States Congress, House Committee on Ways and Means (1994), The 1994 Green Book Overview of Entitlement Programs, Washington, D.C.: U.S. Government Printing Office.

United States Congress, House Committee on Ways and Means (1998), The 1998 Green Book Overview of Entitlement Programs, Washington, D.C.: U.S. Government Printing Office.

Zelnik, Melvin and John F. Kantner (1980), "Sexual Activity, Contraceptive Use and Pregnancy among Metropolitan-Area Teenagers: 1971-1979," Family Planning Perspectives 12, pp. 230237. 
Figure 1

Birth Rates for Single, Less Educated Mothers (Ages 15-45) - CPS

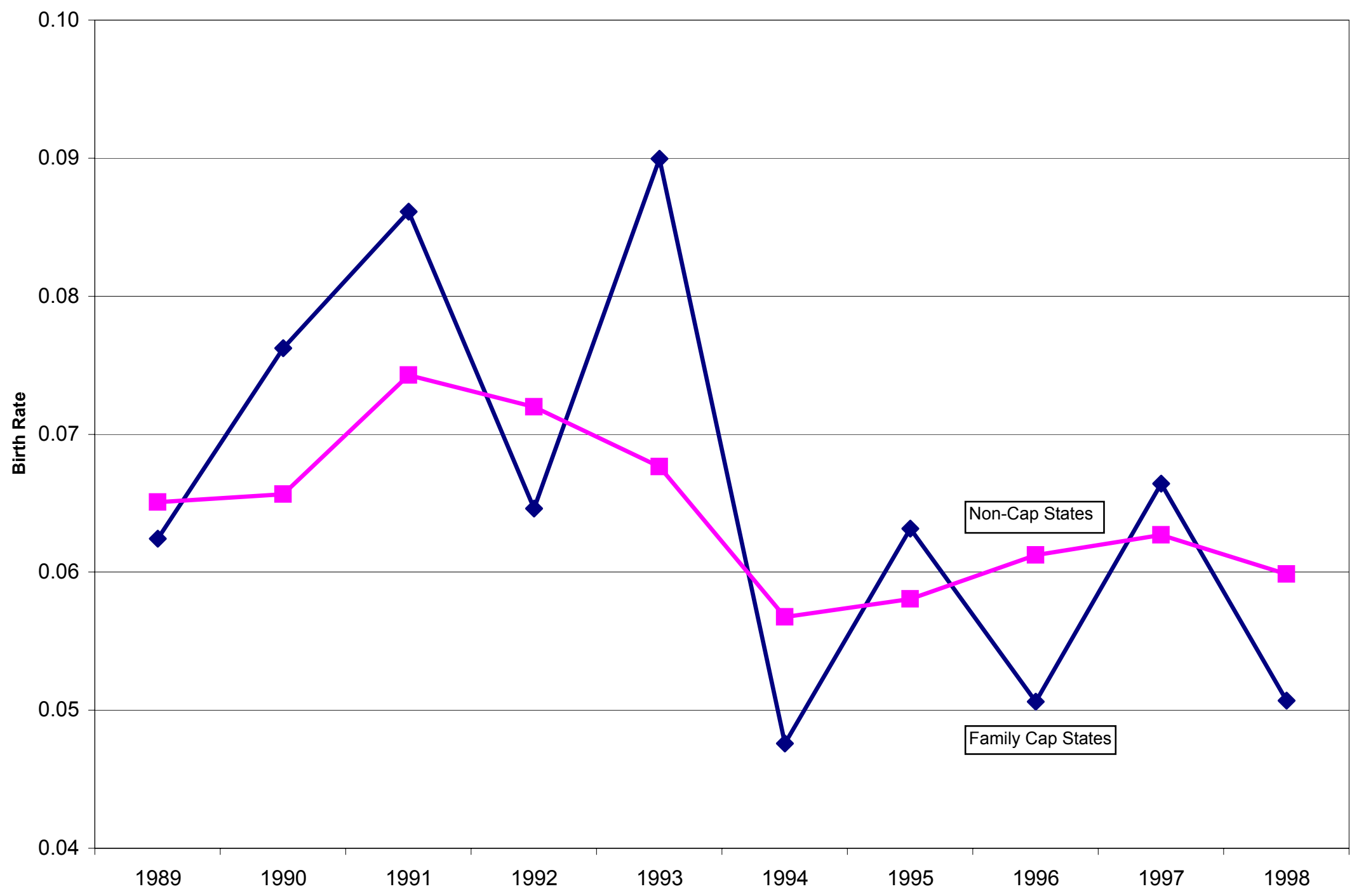


Table 1

States with Family Cap Policies as of 1998

In Order of Implementation Date

\begin{tabular}{|c|c|c|c|}
\hline State & $\begin{array}{c}\text { Family Cap } \\
\text { Implementation Date }\end{array}$ & $\begin{array}{l}\text { AFDC } \\
\text { Waiver }\end{array}$ & $\begin{array}{l}\text { TANF } \\
\text { Rule } \\
\end{array}$ \\
\hline New Jersey & Oct-92 & $\mathrm{X}$ & \\
\hline Georgia & Jan-94 & $X$ & \\
\hline Arkansas & Jul-94 & $X$ & \\
\hline Indiana & May-95 & $X$ & \\
\hline Virginia & Jul-95 & $X$ & \\
\hline Delaware & Oct-95 & $X$ & \\
\hline Mississippi & Oct-95 & $X$ & \\
\hline Arizona & Nov-95 & $X$ & \\
\hline Massachusetts & Nov-95 & $X$ & \\
\hline Nebraska & Nov-95 & $X$ & \\
\hline Illinois & Dec-95 & $X$ & \\
\hline Connecticut & Jan-96 & $X$ & \\
\hline Wisconsin* & Jan-96 & $X$ & \\
\hline Maryland & Mar-96 & $X$ & \\
\hline North Carolina & Jul-96 & $X$ & \\
\hline Tennessee & Sep-96 & $X$ & \\
\hline Florida & Oct-96 & & X \\
\hline Oklahoma & Oct-96 & & $X$ \\
\hline South Carolina & Oct-96 & & $X$ \\
\hline Wyoming & Feb-97 & & $X$ \\
\hline Idaho* & Jul-97 & & $\mathrm{X}$ \\
\hline California & Aug-97 & $X$ & \\
\hline North Dakota & Jul-98 & & X \\
\hline
\end{tabular}

Sources:

(1) The Urban Institute (May 1998). "One Year After Federal Welfare Reform: A Description of State Temporary Assistance for Needy Families (TANF) Decisions as of October 1997."

(2) State of Wyoming Department of Family Services

*Idaho and Wisconsin have flat benefit structures under their TANF plans, resulting in an implicit family cap. 
Table 2

Selected State Characteristics (1992 and 1996)

\begin{tabular}{|c|c|c|c|c|c|c|c|c|c|}
\hline \multirow[b]{2}{*}{ State } & \multicolumn{3}{|c|}{ AFDC Benefit Levels } & \multicolumn{3}{|c|}{ Abortion Providers } & \multicolumn{3}{|c|}{ Unemployment Rate } \\
\hline & 1992 & 1996 & $\%$ Change & 1992 & 1996 & $\%$ Change & 1992 & 1996 & \% Change \\
\hline \multicolumn{10}{|l|}{ Family Cap States } \\
\hline Arkansas & 204 & 182 & $-11 \%$ & 8 & 6 & $-25 \%$ & 7.2 & 5.4 & $-25 \%$ \\
\hline Georgia & 280 & 249 & $-11 \%$ & 55 & 41 & $-25 \%$ & 6.9 & 4.6 & $-33 \%$ \\
\hline Indiana & 288 & 256 & $-11 \%$ & 19 & 16 & $-16 \%$ & 6.5 & 4.1 & $-37 \%$ \\
\hline New Jersey & 424 & 377 & $-11 \%$ & 88 & 94 & $7 \%$ & 8.4 & 6.2 & $-26 \%$ \\
\hline Virginia & 354 & 315 & $-11 \%$ & 64 & 57 & $-11 \%$ & 6.4 & 4.4 & $-31 \%$ \\
\hline \multicolumn{10}{|l|}{ Non-Cap States } \\
\hline \multicolumn{10}{|l|}{ Northeast } \\
\hline Connecticut & 680 & 566 & $-17 \%$ & 43 & 40 & $-7 \%$ & 7.5 & 5.7 & $-24 \%$ \\
\hline Maine & 453 & 372 & $-18 \%$ & 17 & 16 & $-6 \%$ & 7.1 & 5.1 & $-28 \%$ \\
\hline Massachusetts & 539 & 503 & $-7 \%$ & 64 & 51 & $-20 \%$ & 8.5 & 4.3 & $-49 \%$ \\
\hline New Hampshire & 516 & 490 & $-5 \%$ & 16 & 16 & $0 \%$ & 7.5 & 4.2 & $-44 \%$ \\
\hline New York* & 640 & 570 & $-11 \%$ & 289 & 266 & $-8 \%$ & 8.5 & 6.2 & $-27 \%$ \\
\hline Pennsylvania & 421 & 375 & $-11 \%$ & 81 & 61 & $-25 \%$ & 7.5 & 5.3 & $-29 \%$ \\
\hline Rhode Island & 554 & 493 & $-11 \%$ & 6 & 5 & $-17 \%$ & 8.9 & 5.1 & $-43 \%$ \\
\hline \multicolumn{10}{|l|}{ South } \\
\hline Alabama & $\$ 149$ & $\$ 146$ & $-2 \%$ & 20 & 14 & $-30 \%$ & 7.3 & 5.1 & $-30 \%$ \\
\hline District of Columbia & 409 & 374 & $-9 \%$ & 15 & 18 & $20 \%$ & 8.4 & 8.5 & $1 \%$ \\
\hline Kentucky & 228 & 233 & $2 \%$ & 9 & 8 & $-11 \%$ & 6.9 & 5.6 & $-19 \%$ \\
\hline Louisiana & 190 & 169 & $-11 \%$ & 17 & 15 & $-12 \%$ & 8.1 & 6.7 & $-17 \%$ \\
\hline Maryland & 377 & 332 & $-12 \%$ & 51 & 47 & $-8 \%$ & 6.6 & 4.9 & $-26 \%$ \\
\hline North Carolina & 272 & 242 & $-11 \%$ & 86 & 59 & $-31 \%$ & 5.9 & 4.3 & $-27 \%$ \\
\hline Oklahoma & 341 & 273 & $-20 \%$ & 11 & 11 & $0 \%$ & 5.7 & 4.1 & $-28 \%$ \\
\hline South Carolina & 210 & 178 & $-15 \%$ & 18 & 14 & $-22 \%$ & 6.2 & 6.0 & $-3 \%$ \\
\hline Tennessee & 185 & 165 & $-11 \%$ & 33 & 20 & $-39 \%$ & 6.4 & 5.2 & $-19 \%$ \\
\hline Texas & 184 & 167 & $-9 \%$ & 79 & 64 & $-19 \%$ & 7.5 & 5.6 & $-25 \%$ \\
\hline West Virginia & 249 & 225 & $-10 \%$ & 5 & 4 & $-20 \%$ & 11.3 & 7.5 & $-34 \%$ \\
\hline \multicolumn{10}{|l|}{ Other Non-Cap States } \\
\hline Alaska & 924 & 821 & $-11 \%$ & 13 & 8 & $-38 \%$ & 9.1 & 7.8 & $-14 \%$ \\
\hline Hawaii & 666 & 634 & $-5 \%$ & 52 & 44 & $-15 \%$ & 4.5 & 6.4 & $42 \%$ \\
\hline Idaho & 315 & 282 & $-10 \%$ & 9 & 7 & $-22 \%$ & 6.5 & 5.2 & $-20 \%$ \\
\hline Kansas & 422 & 382 & $-10 \%$ & 15 & 10 & $-33 \%$ & 4.2 & 4.5 & $7 \%$ \\
\hline Montana & 390 & 378 & $-3 \%$ & 12 & 11 & $-8 \%$ & 6.7 & 5.3 & $-21 \%$ \\
\hline Nevada & 372 & 310 & $-17 \%$ & 17 & 14 & $-18 \%$ & 6.6 & 5.4 & $-18 \%$ \\
\hline New Mexico & 324 & 346 & $7 \%$ & 20 & 13 & $-35 \%$ & 6.8 & 8.1 & $19 \%$ \\
\hline North Dakota & 401 & 384 & $-4 \%$ & 1 & 1 & $0 \%$ & 4.9 & 3.1 & $-37 \%$ \\
\hline Ohio & 334 & 303 & $-9 \%$ & 45 & 37 & $-18 \%$ & 7.2 & 4.9 & $-32 \%$ \\
\hline Washington & 531 & 486 & $-8 \%$ & 65 & 57 & $-12 \%$ & 7.5 & 6.5 & $-13 \%$ \\
\hline
\end{tabular}

Sources:

(1) Henshaw, Stanley K. (1998), "Abortion Incidence and Services in the United States, 1995-1996," Family Planning Perspectives 30 , pp. $263-270$ \& 287.

(2) 1998 "Greenbook," U.S. Congress, House Committee on Ways and Means

(3) 1998 and 1994 "Statistical Abstract of the United States," U.S. Census Bureau

${ }^{*}$ Average of benefits in New York City and Suffolk County 
Table 3

Comparison of Birth Rates in Family Cap and Non-Family Cap States

\begin{tabular}{|c|c|c|c|c|c|}
\hline & Pre P & $\begin{array}{l}\text { iod } \\
\text { Sample } \\
\text { Size }\end{array}$ & Post F & $\begin{array}{l}\text { riod } \\
\text { Sample } \\
\text { Size }\end{array}$ & $\begin{array}{c}\text { Post-Pre } \\
\text { (Difference) }\end{array}$ \\
\hline \multicolumn{6}{|l|}{ Family Cap States } \\
\hline Arkansas & $6.8 \%$ & 659 & $7.9 \%$ & 324 & $1.1 \%$ \\
\hline Georgia & $6.6 \%$ & 897 & $7.6 \%$ & 234 & $1.0 \%$ \\
\hline Virginia & $6.0 \%$ & 831 & $3.1 \%$ & 154 & $-3.0 \%$ \\
\hline South Total & $6.4 \%$ & 2,387 & $6.7 \%$ & 712 & $0.3 \%$ \\
\hline Indiana & $9.2 \%$ & 790 & $2.2 \%$ & 94 & $-7.1 \%$ \\
\hline New Jersey & $7.5 \%$ & 1,405 & $5.0 \%$ & 1,086 & $-2.5 \%$ \\
\hline Total & $7.3 \%$ & 4,582 & $5.5 \%$ & 1,892 & $-1.7 \%$ \\
\hline \multicolumn{6}{|l|}{ Non-Cap States } \\
\hline South & $6.9 \%$ & 12,180 & $5.8 \%$ & 2,143 & $-1.1 \%$ \\
\hline Northeast & $6.9 \%$ & 6,628 & $5.8 \%$ & 5,749 & $-1.1 \%$ \\
\hline Total & $6.9 \%$ & 27,674 & $5.8 \%$ & 7,455 & $-1.0 \%$ \\
\hline
\end{tabular}

Notes: (1) The sample consists of single, less educated women with children (ages 15-45).

(2) All estimates use sample weights provided by the CPS. 


\section{Table 4}

Probit Regressions for Probability of Out-of-Wedlock Birth Current Population Survey, Outgoing Rotation Group Files (1989-1999)

(1)

Sample

Age

Age Squared

Black

Hispanic

Asian

Native American

Never Married

High School Graduate

Number of Previous

Children

Number of Previous

Children Squared

Live with Parents
U.S.

0.0165

$(0.0132)$

[0.0019]

$-0.0013$

$(0.0002)$

[-0.0001]

0.2185

$(0.0253)$

[0.0250]

0.1558

$(0.0445)$

[0.0178]

0.2333

$(0.0960)$

[0.0267]

0.3315

$(0.0826)$

[0.0380]

0.0501

$(0.0208)$

[0.0057]

$-0.1852$

$(0.0243)$

[-0.0212]

$-0.1661$

$(0.0300)$

[-0.0190]

0.0258

$(0.0046)$

[0.0030]

$-0.2161$

(0.0259)

[-0.0247]
(2)

U.S.

0.0167

$(0.0152)$

[0.0019]

$-0.0014$

$(0.0003)$

[-0.0002]

0.2194

(0.0275)

[0.0251]

0.1563

(0.0367)

[0.0179]

0.232

(0.1046)

[0.0266]

0.332

(0.0641)

[0.0380]

0.0502

(0.0253)

[0.0057]

$-0.1851$

$(0.0217)$

[-0.0212]

$-0.1666$

(0.0281)

[-0.0191]

0.0258

(0.0045)

[0.0030]

$-0.2154$

(0.0294)

[-0.0247]
(3)

South

(4)

South

$-0.0250$

0.0376

(0.0229)

(0.0229)

$(0.0250)$

[-0.0030]

[-0.0029]

[0.0042]

$-0.0007$

$-0.0007$

$-0.0016$

$(0.0004)$

(0.0004)

$(0.0004)$

[-0.0001]

[-0.0001]

[-0.0002]

$\begin{array}{lll}0.2419 & 0.2433 & 0.1956\end{array}$

$(0.0417)$

$(0.0418)$

$(0.0455)$

[0.0279]

[0.0280]

[0.0218]

0.2708

0.2696

0.1238

$(0.0704)$

$(0.0703)$

(0.0510)

[0.0312]

[0.0310]

[0.0138]

0.2509

0.2435

0.2897

$(0.2370)$

$(0.2379)$

$(0.1583)$

[0.0289]

[0.0280]

[0.0323]

0.2452

0.2445

$-0.1472$

(0.1499)

(0.1500)

(0.2875)

[0.0282]

[0.0281]

[-0.0164]

0.0285

0.0285

0.0601

(0.0396)

(0.0396)

(0.0423)

[0.0033]

[0.0033]

[0.0067]

$-0.1418$

$-0.1424$

$-0.2152$

(0.0330)

(0.0330)

(0.0370)

[-0.0163]

[-0.0164]

[-0.0240]

$-0.1081$

$-0.1095$

$-0.1958$

0.0414

(0.0415)

(0.0502)

[-0.0124]

[-0.0126]

[-0.0219]

$$
0.0177
$$

0.0178

0.0273

0.0065

(0.0065)

(0.0084)

[0.0020]

[0.0020]

[0.0030]

$-0.1758$

$-0.1759$

$-0.2324$

(0.0425)

(0.0425)

(0.0514)

[-0.0202]

[-0.0202]

[-0.0259] 
Table 4

(continued)

(1)

(2)

(3)

(4)

(5)

\begin{tabular}{lc}
\hline Family Cap State*Post & 0.0360 \\
Period & $(0.0784)$ \\
& {$[0.0041]$}
\end{tabular}

Arkansas*Post Period

0.1838

0.2237

(0.1392)

$(0.1524)$

[0.0210]

[0.0257]

Georgia*Post Period

0.2489

0.2767

(0.1532)

$(0.1605)$

[0.0285]

[0.0318]

Indiana*Post Period

$-0.4929$

$(0.3356)$

[-0.0564]

New Jersey ${ }^{\star}$ Post Period

0.0163

$-0.0608$

$(0.1021)$

(0.0991)

[0.0019]

[-0.0068]

Virginia*Post Period

$-0.2895$

$-0.2666$

$(0.2256)$

$(0.2318)$

[-0.0331]

[-0.0307]

Southern Family Cap

0.1439

State *Post Period

(0.1071)

[0.0166]

Sample Birth Rate

$$
0.0654
$$

0.0654

0.0662

0.0662

0.0627

Sample Size

41,612

41,612

17,427

17,427

14,869

Log Likelihood

$-8,922.62$

$-8,918.10$

$-3,754.99$

$-3,752.53$

$-3,116.79$

Notes: (1) The sample consists of single, less educated women with children (ages 15-45).

(2) The dependent variable is equal to 1 if the woman has a birth in the previous year.

(3) Standard errors are in parentheses below the coefficient estimates, and probability derivatives (marginal effects) are in brackets below the standard errors. (4) Each equation includes state and year fixed effects, post-period dummy, unemployment rates, and maximum AFDC benefit levels. 


\section{Table 5}

Probit Regressions for Probability of Out-of-Wedlock Birth including Time Trends Current Population Survey, Outgoing Rotation Group Files (1989-1999)

(1)

Sample

Family Cap State*Time Trend

Family Cap State*Post Period
U.S.

$$
\begin{gathered}
0.0166 \\
(0.0259) \\
{[0.0019]}
\end{gathered}
$$

$-0.0334$

$(0.1558)$ $[-0.0038]$
(2)

South

0.0314

$(0.0261)$

[0.0036]

0.0185

$(0.1484)$

[0.0021]

(3)

Northeast
0.0616
(0.0408)
[0.0069]

$-0.2914$

(0.1843)

[-0.0325]

\begin{tabular}{ccc}
0.0655 & 0.0662 & 0.0627 \\
41,612 & 17,427 & 14,869 \\
$-8,922.27$ & $-3,754.27$ & $-3,115.65$ \\
\hline
\end{tabular}

Notes: (1) The sample consists of single, less educated women with children (ages 15-45).

(2) The dependent variable is equal to 1 if the woman has a birth in the previous year.

(3) Standard errors are in parentheses below the coefficient estimates, and probability derivatives (marginal effects) are in brackets below the standard errors. (4) Each equation includes all controls used in Table 4. 
Table 6

Probit Regressions for Probability of Birth including Married Women Current Population Survey, Outgoing Rotation Group Files (1989-1999)

(1)

(2)

(3)

\begin{tabular}{lccc}
\hline \multirow{3}{*}{ Sample } & AR, GA, IN, & & \\
& NJ, VA & AR, GA, VA & NJ \\
Single Woman & -0.2084 & -0.1915 & -0.2632 \\
& $(0.0500)$ & $(0.0713)$ & $(0.0907)$ \\
& {$[-0.0227]$} & {$[-0.0200]$} & {$[-0.0296]$} \\
Single Woman*Post Period & -0.1443 & 0.0316 & -0.1738 \\
& $(0.0733)$ & $(0.1127)$ & $(0.1069)$ \\
& {$[-0.0157]$} & {$[0.0033]$} & {$[-0.0195]$} \\
& & & \\
Sample Birth Rate & & & \\
Sample Size & 0.0625 & 0.0597 & 0.0650 \\
Log Likelihood & 20,429 & 9,836 & 7,491 \\
\hline
\end{tabular}

Notes: (1) The sample consists of single and married, less educated women with children (ages 15-45). (2) The dependent variable is equal to 1 if the woman has a birth in the previous year. (3) Standard errors are in parentheses below the coefficient estimates, and probability derivatives (marginal effects) are in brackets below the standard errors. (4) Each equation includes all controls used in Table 4. 
Table 7

Probit Regressions for Probability of Birth including Married Women

Current Population Survey, Outgoing Rotation Group Files (1989-1999)

\begin{tabular}{lccc} 
& $\mathbf{( 1 )}$ & $\mathbf{( 2 )}$ & $\mathbf{( 3 )}$ \\
\hline Sample & U.S. & South & Northeast \\
Single Woman & & & -0.2996 \\
& -0.2396 & -0.1637 & $(0.0347)$ \\
& $(0.0243)$ & $(0.0311)$ & {$[-0.0338]$} \\
Single Woman*Post Period & {$[-0.0267]$} & {$[-0.0177]$} & -0.0334 \\
& & & $(0.0583)$ \\
& -0.0609 & -0.1306 & {$[-0.0038]$} \\
Single Woman*Family Cap State & $(0.0393)$ & $(0.0582)$ & 0.0228 \\
& {$[-0.0068]$} & {$[-0.0141]$} & $(0.0716)$ \\
& & & {$[0.0026]$} \\
Family Cap State*Post Period & 0.0368 & -0.0057 & 0.1495 \\
& $(0.0423)$ & $(0.0582)$ & $(0.0764)$ \\
& {$[0.0041]$} & {$[-0.0006]$} & {$[0.0169]$} \\
Single*Family Cap State*Post Period & & & \\
& 0.0874 & -0.0234 & -0.1413 \\
Sample Birth Rate & $(0.0499)$ & $(0.0782)$ & $(0.1220)$ \\
Sample Size & {$[0.0097]$} & {$[-0.0025]$} & {$[-0.0160]$} \\
Log Likelihood & & & \\
\hline
\end{tabular}

Notes: (1) The sample consists of single and married, less educated women with children (ages 15-45).

(2) The dependent variable is equal to 1 if the woman has a birth in the previous year.

(3) Standard errors are in parentheses below the coefficient estimates, and probability derivatives (marginal effects) are in brackets below the standard errors. (4) Each equation includes state and year fixed effects. 